\title{
LA INFORMACIÓN SOBRE EL ORIGEN BIOLÓGICO COMO DERECHO FUNDAMENTAL DE LA PERSONA ${ }^{1}$
}

Ronald Cárdenas Krenz ${ }^{2}$

\section{RESUMEN}

El estudio analiza si las personas concebidas a través de las técnicas de reproducción asistida tienen derecho a conocer su origen biológico, en el marco de los Derechos Fundamentales de todo ser humano, no obstante que en una gran mayoría de países actualmente se niega dicho derecho.

\section{PALABRAS CLAVES}

Fecundación asistida. Derecho a la identidad. Paternidad biológica. Derecho a la verdad. Origen biológico. Bioética. Derecho a la información.

\section{ABSTRACT}

This paper examines whether people conceived through assisted reproductive techniques are entitled to know their biological origin, in the context of the fundamental rights of every human being, even though a large majority of countries currently denies that right.

\section{KEY WORDS}

Assisted fertilization. Right to identity. Biological parents. Right to the Truth. Biological origin. Bioethics. Right to information.

\section{A MANERA DE INTRODUCCIÓN}

Millones de personas han nacido en el mundo en las últimas décadas, producto de la fecundación asistida y existen numerosas empresas que se dedican a ello. Podemos estar o no de acuerdo con dicha práctica, pero lo cierto es que existe y es legal en varios países.

Estos procesos de fecundación in vitro (FIV) se han venido haciendo, por lo general, teniendo como principio fundamental el del anonimato de los "donantes", salvo naturalmente los casos en los que la propia pareja es la que "consigue" un dador 0 donante, para suplir la incapacidad física de uno de ellos (o de ambos) para poder engendrar un hijo.

Así entonces, cuando la pareja que se encuentra en esa situación, acude a un banco de espermios, óvulos o embriones, termina recibiendo el material genético que necesita sin conocer su origen biológico, exponiéndose por tanto a una serie de riesgos, el cual se agrava si tenemos en cuenta que en muchos países no existe un control del Estado respecto a este tipo de actividades.

Ahora bien, para justificar dicho anonimato, se invoca el derecho a la intimidad de los padres, entre otras consideraciones, que muchas veces lo que buscan en el fondo es disimular

\footnotetext{
El presente artículo es un avance preliminar de una investigación sobre la materia que viene realizando el autor.

Profesor Principal y Decano de la Facultad de Derecho de la Universidad Femenina del Sagrado Corazón. Profesor contratado de la Facultad de Derecho de la Universidad de Lima y de la Universidad ESAN. Miembro del Comité de Bioética de la Facultad de Biología de la Universidad Nacional Mayor de San Marcos. Correos electrónicos: ronald@unife.edu.pe y rckrenz@speedy.com.pe.
} 
más bien algún interés comercial por parte de las empresas que se dedican a este tipo de actividades.

Así, la persona nacida mediante una FIV desconoce su origen genético $\mathrm{y}$, más todavía, suele desconocer el propio hecho de haber nacido mediante un procedimiento de este tipo.

Dado que el primer bebé probeta, Louise Brown, nació en Inglaterra en 1978, hace unos 35 años, la gran mayoría de los nacidos producto de una FIV son todavía gente muy joven para sospechar sobre sus orígenes y reclamar se les informe, mas podemos avizorar que, en un tiempo no muy lejano, estas personas, en la medida que vayan teniendo más edad, se preocuparán por saber sus orígenes, como ya han venido apareciendo algunos casos en Australia y Estados Unidos, por ejemplo.

¿Puede decirse que existe un derecho, que tenemos todos, a conocer nuestro origen biológico? Creemos que sí, tal como pretenderemos sustentar en las siguientes líneas; empero, ello no es fácil, pues deben superarse algunas trabas legales $y$ sociales, amén de los intereses económicos que subyacen a la materia. $^{3}$

Adicionalmente, coincidiendo con Aída Kemelmajer ${ }^{4}$, estimamos que el análisis del tema exige un debate interdisciplinario, ya que compromete aspectos éticos, jurídicos, psicológicos, médicos, filosóficos y sociológicos. En tal virtud, consideramos que el escenario más propicio para ello, teniendo en cuenta la complejidad de la materia y la naturaleza de la disciplina, es el que puede ofrecernos la perspectiva bioética.

INVOCABILIDAD DEL DERECHO A LA INTIMIDAD PARA OCULTAR A UNA PERSONA SU ORIGEN BIOLÓGICO EN EL CASO DE APLICACIÓN DE TÉCNICAS DE REPRODUCCIÓN ASISTIDA

Es cierto que existen varios detalles vinculados con la concepción que son de estricto interés solo de los padres, mas ¿puede hacerse extensivo ello al conocimiento del hijo acerca de quiénes son sus padres? Consideramos que no, por cuanto una cosa es la información sobre cuestiones estrictamente personales y otra cosa cuando dicha información implica sustancialmente a terceros, más todavía en este caso que atañe a su vida misma, a su salud, a su biografía, a su existencia.

Ello puede advertirse mejor si tenemos en cuenta los motivos que pueden estar detrás de la búsqueda que hace una persona de sus orígenes, que pueden ser su interés en conocer su mayor predisposición a ciertas enfermedades, saber de determinados riesgos hereditarios de los que puede ser importante estar advertidos, evitar relaciones incestuosas y otras cuestiones esenciales que justifican el querer acceder a nuestro verdadero origen, que incluyen, junto con motivos de salud, razones emocionales, sociales, afectivas y psicológicas.

\section{Algunas Consideraciones legales SOBRE EL TEMA}

La mayoría de legislaciones, al establecer el principio del anonimato, niega la posibilidad de que una persona nacida mediante una FIV pueda conocer quién es su padre biológico, no solo para proteger algo que sus padres quieren mantener en secreto, sino también para proteger al dador y evitarle problemas futuros de reclamos de paternidad que en absoluto le interesan asumir.

No obstante, es interesante mencionar que la Convención sobre los Derechos del Niño establece en su artículo 3 que en todas las medidas concernientes a los niños debe darse una consideración primordial al interés superior del niño, agregando luego, en el primer párrafo de su artículo 7 que: “1. El niño será inscrito inmediatamente después de su nacimiento y tendrá derecho desde que nace a un nombre, a adquirir una nacionalidad y, en la medida de lo posible, a conocer a sus padres y a ser cuidado por ellos".

Asimismo, el primer párrafo del artículo 8 dispone que "1. Los Estados Partes se comprometen a respetar el derecho del niño a preservar su identidad, incluidos la nacionalidad, el nombre y las relaciones familiares de conformidad con la ley sin injerencias ilícitas".

Queda claro entonces el reconocimiento que hace la Convención a que el niño tiene derecho a conocer sus orígenes; aunque

3 Por ejemplo, como dice Olguín, A. (“Los derechos de filiación en las técnicas de fecundación artificial”. En: La Familia: Naturaleza y Régimen Jurídico en el Siglo XX, .2007: pp. 14), existe un conflicto "entre el instituto de la filiación tal y como se encuentra regulado y muchísimos supuestos provocados por el uso de estas técnicas".

4 Kemelmajer, Aída. El nuevo Derecho de Familia, 2010, pp. 86. 
no puede dejarse de mencionar que la frase "en la medida de lo posible", despierta diferencias en cuanto a sus alcances e interpretación. ${ }^{5}$

Asimismo, tenemos el artículo 8 de la Convención Europea de Derechos del Hombre, que reconoce el derecho de toda persona a su vida privada y a la información que le es relativa. Otro texto de interés es la Recomendación No. 1443/2000 del Consejo de Europa que se refiere a que se debe "asegurar el derecho de los niños adoptados a conocer sus propios orígenes, a más tardar, al llegar a la mayoría de edad y a eliminar de la legislación nacional toda cláusula contraria".

Por otro lado, algunos Estados en EE.UU., cuentan con legislaciones que permiten a los hijos adoptados el pleno acceso a los datos identificativos de los padres biológicos, siendo la excepción la confidencialidad. ${ }^{6}$ También en dicho país, recientemente se conoció el caso de una persona a quien no solo se le reconoció el derecho a conocer su origen biológico, sino también a recibir alimentos por parte de su padre biológico. Sin embargo, en este caso, el sustento, más que en el derecho a conocer el origen en sí, se puso en que la donación se hizo en forma privada y no a través de un banco de esperma oficialmente establecido.

En cambio, en Francia, como se sabe, se admite la figura del "parto anónimo", que mantiene en secreto el nacimiento en favor de la madre que por razones personales no desea criar al niño y que nadie pueda conocer de ella.

En Suecia, en 1985, se aprobó una ley a efectos que los hijos procedentes de una FIV heteróloga, tengan derecho, al llegar a los 18 años, a conocer el nombre del padre o la dadora de gametos, para disminuir así los problemas psicológicos que pueden producirse y lograr una adecuada integración de la personalidad del niño. ${ }^{7}$ En Holanda, existe una ley aprobada en el mismo sentido, explicando el ministro holandés de entonces la necesidad del nacido mediante una inseminación artificial de que conozca su identidad y no sólo las características generales de sus padres, al amparo de las consecuencias negativas que sufren los niños por desconocer su origen. ${ }^{8}$

Es interesante señalar que, hace poco, a principios del 2013, en Alemania, país en donde existen unas 100.000 personas concebidas mediante la donación de esperma, un tribunal ha fallado, en el caso de Sarah P., estableciendo que no se puede garantizar el anonimato de los donantes (padres biológicos) ignorando el derecho a la identidad. ${ }^{9}$

De esta manera, la justicia alemana ha reconocido el derecho a la identidad como un derecho humano, por encima de cualquier derecho al anonimato o intimidad que pueda pretender invocarse. Es de hacer notar que el Tribunal Constitucional ya había confirmado en un caso anterior la obligación por principio de informar sobre los datos de donantes anónimos. ${ }^{10}$

En Dinamarca, por su parte, los donantes tienen la posibilidad de mantener el anonimato, al igual que en los Países Bajos y España. En Chile, Argentina ${ }^{11}$ o Perú tampoco está reconocido este derecho.

Sin embargo, en el caso de Argentina, es de mencionar que el artículo 4 de la Ley 23.511, por la que se crea en dicho país el Banco Nacional de Datos Genéticos, prescribe en su primer párrafo: "cuando fuese necesario determinar en juicio la filiación de una persona y la pretensión apareciera verosí-

5 Para algunos, por ejemplo, se refiere a condiciones materiales, mientras para otros se refiere también a limitaciones legales, con lo que se termina mediatizando este derecho, al dejarlo al libre albedrío de lo que cada Estado determine.

6 García, L. y L..De la Fuente. "El derecho del adoptado a conocer sus orígenes en España y en el Derecho Comparado", pp. 29-30.

7 Marcó, B. y M. Tarasco. “Fecundación in vitro y manipulación de embriones”, 2009, pp. 252.

8 Vila-Coro, M.D. Huérfanos biológicos. El hombre y la mujer ante la reproducción artificial, 1997: pp. 84.

9 La mujer, de 22 años, había tenido una sentencia desfavorable en primera instancia ante la Audiencia Provincial de Essen (oeste de Alemania) en su reclamo de su derecho a ser informada sobre la identidad de su padre biológico. Con lo resuelto el 06.02.2013, el Tribunal Superior de Hamm, en el Estado de Renania del Norte-Westfalia, sentó un precedente, al reconocerle el derecho de ser informada sobre la identidad de su padre por una clínica de la ciudad de Essen, en la cual fue concebida a través de una donación de esperma en 1990. Si bien, aparentemente las actas en donde figuraba el dato requerido, lo importante aquí es el principio que se consagra, aparte del deber de los médicos de tratar de conseguir la información necesaria. (Lütticke, M. y C. Papaleo. "Hijos de donantes de esperma exigen respuestas”, 2013: 1).

10 http://www.eluniversal.com.mx/notas/901099.html. (Consultada el 16.03.2013).

11 Para más detalle, véase: http://www.lavoz.com.ar/ciudadanos/alemania-piden-pension-alimentaria-donante-esperm. (Consultada el 05.03.2013). 
mil o razonable... se practicará el examen genético que será valorado por el juez teniendo en cuenta las experiencias y enseñanzas científicas en la materia; la negativa a someterse a los exámenes y análisis necesarios constituirá indicio contrario a la posición sustentada por el renuente". ${ }^{12}$

En el caso peruano, el artículo 396 del Código Civil peruano dispone que "El hijo de mujer casada no puede ser reconocido sino después de que el marido impugne la paternidad y obtenga sentencia favorable", lo que implica entonces que la ley privilegia la presunción de paternidad matrimonial a pesar de que la realidad diga que existe más bien una paternidad extramatrimonial.

Sin embargo, esta norma, se viene advirtiendo -sobre todo por parte de algunos juecescolisionaría con lo dispuesto en el inciso 1 del artículo 2 de la Constitución de 1993, el cual establece que toda persona tiene derecho a la identidad.

Además, existen interesantes pronunciamientos del Tribunal Constitucional que reconocen el derecho de toda persona a investigar su propia filiación; si bien estos fallos han sido dados en el marco de casos vinculados con el tema del Derecho de Familia, sus consideraciones son perfectamente extensivas al co- nocimiento de la verdad biológica como derecho individual. ${ }^{13}$

En el caso de Venezuela, el art. 56 de la Constitución declara que "Toda persona tiene derecho a un nombre propio, al apellido del padre y el de la madre, y a conocer la identidad de los mismos". En Bolivia, el Código del Niño afirma que todo niño, niña o adolescente que haya sido adoptado tiene derecho a conocer los antecedentes de su adopción y referencias de su familia de origen". El Código de la Infancia de Colombia señala que todo adoptado tiene derecho a conocer su origen y el carácter de su vínculo familiar. ${ }^{14}$

\section{DeRECHO A LA IDENTIDAD, AUTONOMÍA Y VERDAD BIOLÓGICA}

Toda persona tiene derecho a la identidad, el cual surge en la jurisprudencia italiana a mediados de los años setenta, pudiendo definirse la identidad personal, siguiendo a Fernández Sessarego, como "todo aquello que hace que cada cual sea "uno mismo" y "no otro". ${ }^{15}$

Dentro de este concepto, puede incluirse tanto el derecho a conocer la identidad biológica como el derecho a la determinación de la relación paterno-filial que, si bien están relacionados, son dos cosas distintas.
Para efectos del presente trabajo, lo que nos interesa es el derecho a conocer la identidad biológica, dejando aparte el tema del reconocimiento legal de la filiación.

Como cuestión conceptual, es de señalar que puede distinguirse el origen genético del origen biológico, siendo que el primero se refiere al mero dato técnico, vinculado con la herencia genética; mientras que el segundo abarca también los vínculos familiares y afectivos que son parte de la propia historia de una persona. ${ }^{16}$

Es oportuno citar aquí a García y De la Fuente, quienes expresan las razones que llevan a una persona al deseo de saber, señalando que no tienen que ver con que el adoptado no se sienta bien con su familia adoptiva, sino que responden más bien, a cuestiones vinculadas con el sentimiento de identidad del sujeto. ${ }^{17}$ Ello mismo -agregamos- puede hacerse extensivo a las personas nacidas mediante una FIV.

Por otro lado, si bien no cabe duda que la autonomía de la voluntad es un elemento esencial del derecho, mal puede sostenerse una supuesta aplicación del mismo cuando la persona no tiene una debida información respecto a la decisión que tiene que tomar. ${ }^{18}$

12 La Gaceta. Tucumán, Argentina, 02.10.2007 (Consultada el 13.03.2013).

13 Para más detalle, véase: Arias Stella, F. Derechos Humanos y las sentencias del Tribunal Constitucional que consagran el derecho a investigar la propia filiación, 2012.

14 Kemelmajer, A., 2010, pp. 90.

15 Fernández Sesarego, C. Derecho a la identidad personal. Buenos Aires, Astrea, 1992: pp. 113.

16 Kemelmajer, A. El nuevo Derecho de Familia, 2010, pp. 85.

García y De la Fuente, s/a,19-20.

1 Por ejemplo, cuando se habla de la fecundación in vitro, existe la creencia errónea de que su efectividad sea muy alta, siendo que en verdad es poco eficaz (apenas un $20 \%$ a nivel mundial), costosa e implica un alto coste de vidas de embriones humanos (Marcó y Tarasco, 2009, pp. 227, 239). 
Finalmente, podemos decir con Bach y Tarasco:

"Si el hijo procede de donantes en una fecundación heteróloga, es decir, cuando existe más de dos padres, si al crecer el hijo decide conocer la identidad del progenitor biológico, debería tener el derecho jurídico a ello, y desde el punto de vista ético lo tiene siempre, ya que cuando se alcanza la edad de la razón, hay una necesidad profundamente enraizada en el ser humano de conocer a su progenitor, para no crear un vacío en su ascendencia. Todos tenemos la necesidad de situarnos en relación a una historia o una familia, lo que forma parte esencial de la propia identidad.". ${ }^{19}$

\section{Derechos Fundamentales $Y$ DERECHO DE TODA PERSONA A CONOCER SUS ORÍGENES}

Junto con el derecho a la identidad como sustento para que una persona pueda acceder al conocimiento de su origen biológico, puede agregarse también la consideración del principio del interés superior del niño, el respeto de la dignidad de la persona humana, el derecho a la información, el derecho a la salud y el derecho a la verdad.

Menciona Vila-Coro que, en 1986, en una reunión en Italia bajo los auspicios del Consejo de Europa, una reunión del Comité de Expertos (CAHBI) sobre genética humana y su problemática jurídica, declaró su oposición rotunda al anonimato del donante de gametos y de embriones, afirmando que el derecho del niño a conocer su identidad biológica es un derecho humano.

Como señala Plácido, se debe "afianzar el derecho de toda persona a conocer y preservar su identidad filiatoria, con prescindencia de las circunstancias fácticas en las que se desarrolló el acto procreativo, por la consideración primordial del interés superior del niño", dándose preferencia a la realidad biológica independientemente de que la impugnación sea matrimonial o extramatrimonial. ${ }^{20}$

Este derecho también se sustenta en el derecho a la protección de los datos personales que, como señala Romeo Casabona, se extiende "a cualquier información genética individual, y corresponde al individuo decir a quién, cómo y con qué extensión puede revelarse tal información". ${ }^{21}$

En cuanto a la pretensión de relacionar el tema con la figura de la donación de órganos, para justificar el tema del anonimato, la analogía parece algo forzada, toda vez que, solo para mencionar una razón, una cosa es donar un órgano y otra los espermatozoides de una persona que constituyen un germen de vida.

Adicionalmente, hay quienes invocan el principio del respeto a los contratos y la autonomía de la voluntad de las personas para preservar el anonimato en las FIV, mas ello puede ser refutado, teniendo en cuenta que la autonomía de la voluntad no es absoluta y que ella se ejerce en el marco del orden público y las buenas costumbres, y del respeto a los derechos de los demás.

Agregado a lo expuesto, vale considerar que, como se señalara en el II Congreso Mundial vasco: La filiación a finales del siglo XX:

“...la relación biológica del nacido de fecundación asistida respecto del donante de gametos tiene una enorme importancia para toda persona, pues determina una herencia genética de la que derivan importantes caracteres hereditarios -ser moreno oscuro o albino, padecer hemofilia o tener una especial proclividad para el cáncer o la depresión-, con notable trascendencia para la persona y en la conformación de su personalidad. Todo ello excede del ámbito de la relación jurídica familiar que es la de filiación, para afectar un derecho fundamental de la persona emparentado con el derecho a conocer el propio origen y con su dignidad personal".22

\section{Otros argumentos relevantes.}

Desde un punto de vista médi$\mathrm{co}$, se puede encontrar sustento para el reconocimiento de este derecho en el llamado principio de "necesidad terapéutica", como también en el ejercicio

\footnotetext{
Marcó y Tarasco, 2009, pp. 250-251.

Plácido, A. "La Evidencia Biológica y la presunción de paternidad matrimonial”, 2010, pp. 212 y 216.

Romeo Casabona, C. "El tratamiento y la protección de los datos genéticos", 2003, pp. 255.

Vila-Coro, 1997, pp. 85.
} 
del derecho al consentimiento informado, toda vez que para poder tomar determinadas decisiones médicas, es necesario que el paciente conozca sus orígenes, a fin de que el consentimiento que pueda dar sea, efectivamente, informado.

Es importante precisar aquí que la propuesta de reconocer el derecho a conocer su origen biológico como atributo de toda persona, no solo tiene que ver con que, por razones médicas, sepa realmente qué riesgos hereditarios de salud pueda tener ${ }^{23}$, pues también es importante considerar que, conforme menciona Xavier Simmons, un estudio hecho por investigadores australianos, sobre la base de niños nacidos entre 1995 y 2012, mediante reproducción asistida, reveló que estos son más proclives a tener defectos de nacimiento en un $32 \%$. Detrás de ello, se mencionan factores asociados con el tratamiento que podrían incrementar el riesgo en nacimientos, incluyendo las mismas causas de infertilidad subyacentes; las propias técnicas de reproducción asistida como los medicamentos usados, cuestiones vinculados con el congelamiento y descongelamiento de los embriones, alteraciones hormonales al tiempo de la implantación, la manipulación de gametos y embriones o una combinación de estos. ${ }^{24}$

Otro dato interesante es la mención que hace Vila-Coro, de un estudio canadiense que llegó a la conclusión de que había más mongólicos entre los hijos nacidos de una fecundación in vitro heteróloga que entre el resto de la población. ${ }^{25}$

A las razones médicas, se agregan razones de tipo psicológico, pues, como señala el psicólogo de la Universidad de Chile, Rubén Araya, citando a Jadva, V. Freeman y otros: "en general los estudios muestran que entre más tarde y más fortuitamente es informado un sujeto de su origen en base a TRA-D más negativos son los sentimientos que emergen frente a los padres y al hecho de haber nacido de esta manera". ${ }^{26}$

Es de mencionar que, como refiere Vila-Coro, investigaciones efectuadas en Estados Unidos, Canadá y Gran Bretaña sobre niños adoptados, confirman claramente que es muy grande su necesidad de conocer su origen, y las posibilidades de obtener ese conocimiento es de la mayor importancia para su desarrollo. También organizaciones y personas vinculadas con temas de adopción en Suecia comparten la misma experiencia. ${ }^{27}$

Dentro de los argumentos en contra de reconocer este derecho, se han esgrimido razones económicas, en tanto la posibilidad de que se revele la identidad del donante, reduciría ostensiblemente la cantidad de dadores, generando tanto mayores costos como que se promocionen mercados negros para conseguir donantes por lo bajo. Si bien esto puede suceder, es un costo que debe afrontarse para salvaguardar un bien superior $y$, en todo caso, un problema que puede abordarse también desde la ley; además de ello, el reconocimiento del derecho al origen, desanimaría a quienes hayan pretendido convertir la dación de semen en una cuestionable forma sin control de ganarse la vida.

Para notar cómo el factor netamente comercial puede ser determinante en los tratamientos de fecundación asisti$\mathrm{da}$, baste mencionar el caso de una clínica de fertilidad que en un aviso publicado en el New York Times, en su sección Money and Business, decía en agosto de 1996, al más puro estilo comercial: "It's a Baby or it's your money back". ${ }^{28}$

Aparte de todo lo expuesto, existen casos que refuerzan con contundencia el cuestionamiento a la preservación del anonimato, como la historia de Bertold Wiesner, director de una clínica de fertilidad británica, de quien se hizo público en abril del 2012, que podría ser el padre de entre 300 y 600 niños, al haber usado su propio esperma para ayudar a más de 1.500 mujeres a concebir un

23 Señala J. Testart que todos poseemos cuatro o cinco genes de enfermedades graves que no se expresan, pero que pueden ser transmitidos por herencia (Testart y Godin, 2001, pp. 40).

24 Symons, X. "Birth defects more likely in IVF children", 2013, pp. 7.

25 Vila-Coro, 1997, p. 21.

26 Araya. "Secreto y anonimato en la reproducción asistida con donación de gametos", 2010, pp 3.

27 Vila-Coro, 1997, pp. 83.

28 Vila-Coro, 1997, pp. 23. 
hijo. Todo comenzó cuando dos personas, asombradas por su parecido con el médico, se sometieron a una prueba de $A D N$, descubriendo que eran hijos del mismo padre, lo que sería solo el hilo de la madeja para empezar a descubrir a otros hermanos.

No se sabe si el motivo fue el deseo del médico de ahorrar "costos" o algún delirio de grandeza. Lo cierto es que Weisner, de nacionalidad austriaca, junto con su esposa, Mary Barton dirigió la Barton Clinic entre 1940 y 1972, año en que murió. ${ }^{29}$

\section{El EJE CENTRAL PARA LA ATENCIÓN DEL PROBLEMA}

En este tema, pareciera que, a lo largo del tiempo, el eje de la atención se ha centrado más en los padres, al considerarse un derecho de ellos el mantener en secreto el origen del hijo que puedan haber tenido por esta vía. No obstante, debe tenerse en cuenta, en cuanto a la relación del hijo con la madre que, como señala Roberto Vásquez, la maternidad debe entenderse en función del hijo y no al revés ${ }^{30}$; hablar, por ejemplo, de que la mujer tienen un derecho al hijo, haría de este último, que es fin en sí mismo, un medio al servicio de los deseos o intereses de otra persona." ${ }^{31}$

Otro eje que se ha considerado es el de la perspectiva de las instituciones de salud que se dedican a este tipo de actividades reproductivas, que ven en la donación anónima la posibilidad de poder tener más donantes.

No puede obviarse que otro eje está en el propio dador del semen, pero pareciera que no ha merecido mayor atención pues, si se ha ofrecido al efecto se deduce su escaso o nulo interés en la paternidad y, más todavía, su preocupación y deseo de no tener que afrontar luego juicios de filiación o alimentos, riesgo del que precisamente lo libera el principio del anonimato. En el ámbito del tema de la FIV, debe tenerse en cuenta no solo la dignidad del niño, sino también la de aquel que permite el uso de de sí como un simple proveedor o fuente de "recursos". ${ }^{32}$

Sin dejar de valorar al total de los sujetos involucrados, consideramos que el eje fundamental aquí debe verse en el propio concebido, que no puede ser tratado como un convidado de piedra, y cuyos legítimos intereses deben anteponerse a los de cualquiera de los otros ejes en los que gira el tema.

Como dice Díaz de Terán Velasco, siguiendo a M.F. Pompedda y A.M. Vega Gutiérrez, la propia dignidad de persona humana del concebido exige el reconocimiento de su soberana autonomía tanto frente a sus padres como frente a la sociedad, agregando que:

“...precisamente, la humanización de la procreación exige estimar el interés del hijo como guía de ponderación. Humanizar, por tanto, no significa confiar a una biotecnología sin restricción ética alguna la misión, sólo aparentemente humanitaria, de encontrar recursos para satisfacer cualquier posible deseo de fabricación de una familia, sino construir responsablemente el fundamento de la sociedad del mañana redescubriendo -muy especialmente en el terreno jurídico- el sentido y las exigencias de las relaciones personales naturales. ${ }^{33}$

\section{A MANERA DE CONCLUSIÓN}

Ocultar a una persona su origen genético frustra el derecho natural de todo individuo de conocer algo tan básico, como

29 http://www.abc.es/20120409/sociedad/abci-donante-esperma-hijos-201204091314.html. (Consultada el 20.03.2013).

30 En tal sentido, "no hay un derecho a transmitir la vida por cualquier medio y a cualquier precio, ya que este derecho sería contrario a la dignidad del hijo, tratándolo como un objeto de propiedad, en vez de cómo un sujeto personal de derechos. El legítimo deseo de tener un hijo, debe ir acompañado de la responsabilidad para buscar las mejores condiciones para su concepción y su desarrollo como persona, reconociendo en primer lugar que el hijo es un don y no un derecho". (Marcó y Tarasco, 2009, pp. 242)

31 Vásquez, 1993.

32 Señala Christian Godín: "El famoso principio de anonimato rebaja al dador al papel de semental. Por cierto, en apariencia vela por el narcisismo herido de las parejas estériles, pero al precio de una negación de la que pocos se atreven a sorprenderse. El aspecto más alienante de la donación de gametos, dice (Jacques Testart), no es que el padre genético no sea el padre social, ni siquiera el secreto a menudo vinculado con ese origen atípico, puesto que muchos niños del adulterio pudieran vivir felices en todas las épocas. Por lo menos en Francia, radica en la prohibición legal de decidir y de saber, porque únicamente la institución médica se arroga la elección de un progenitor y es la única poseedora de tal secreto". (Testart y Godin, 2001: 58-59).

33 Díaz, M. Derecho y nueva eugenesia. 2005, p. 7. 
es saber sus orígenes, independientemente de los intereses morales y económicos que pueden haber detrás de ellos. Por lo demás, se le estaría discriminando respecto al derecho de cualquier persona nacida, concebida mediante la forma tradicional, que tiene la posibilidad de optar saber o no de sus ancestros, yendo asimismo contra el deber que tienen los padres de decir la verdad a sus hijos.

A partir de lo expuesto, podemos concluir que toda persona tiene el derecho de conocer su identidad de origen, su propia historia. "Poder conocer su propia génesis, su procedencia, es aspiración connatural del ser humano que, incluyendo lo biológico, lo trasciende. Tender a encontrar raíces que den razón del presente a la luz del pasado que permita reencontrar una historia única e irrepetible en movimiento $(. . .)^{34}$

Si partimos del presupuesto kantiano de que toda persona es un fin en sí, debemos, justamente, pensando en el concebido mediante una FIV, darle la posibilidad de conocer la verdad de su origen, lo cual no se trata solo del reconocimiento de un derecho más sino que es parte del respeto a su dignidad de persona, siendo el fundamento antropológico de la dignidad el ser tratado como fin en sí. ${ }^{35}$

Resulta interesante en este contexto, citar las palabras de Margaret Brown, hija de un donante anónimo "Soy una persona engendrada por inseminación artificial, alguien que nunca conocerá la mitad de su identidad. ¿Quién soy? es una pregunta difícil de contestar para alguien que ignora de donde viene... Negar a alguien el conocimiento de sus orígenes biológicos es un terrible error". ${ }^{36}$

Como dice Vila-Coro, el hijo de donante anónimo carece de vínculo histórico, al no saber la identidad de su padre referencial, encontrándose en una situación semejante a la del adoptado que no sabe quiénes fueron sus padres naturales.

Por otro lado, no puede dejar de mencionarse que la IAD ha llevado al disimulo y a la mentira, independientemente de sus bondades. ${ }^{37}$

Una de las vías por las que el derecho a conocer la verdad biológica va adquiriendo lenta pero progresivamente, mayor aceptación, es en la judicatura, a raíz de casos como el de una persona demandada por filiación que fue beneficiada con una sentencia favorable, que luego adquirió la calidad de cosa juzgada; de pronto, la madre desea que se haga un nuevo juicio, al amparo de nuevas pruebas reveladas por la tecnología antes inexistente. Se plantea entonces un conflicto entre la "cosa juzga- da" como institución jurídica y el derecho a la identidad. En este tema, coincidimos con Pierri en que cabría la revisión de la sentencia bajo el concepto jurídico de "prueba ignorada", en cuanto existan nuevas pruebas que antes no existían o no eran conocidas en nuestro medio.

Otro criterio es la ponderación de los derechos, determinando cuál principio debe tener mayor peso en el caso concreto, y el principio de la proporcionalidad, por el que toda intervención legislativa en los derechos fundamentales debe ser adecuada para contribuir a la obtención de un fin constitucionalmente legítimo. ${ }^{38}$

Como dice la misma autora, "al encontrarse en colisión estos dos valores constitucionalmente protegidos, la seguridad jurídica por un lado y el derecho a la identidad, con todos los derechos que el primero integra, el segundo debe prevalecer sobre el primero. Ello propicia la adecuación de la verdad jurídica-formal a la verdad biológica, lo cual es, al final de cuentas, una adecuación vinculada a la dignidad de la persona, la igualdad, la intimidad y el libre desarrollo de la personalidad o autonomía". ${ }^{39}$

Así, como dice Roberto Vásquez, a propósito del derecho de las personas a conocer el

34 En: "La filiación y el derecho a la identidad" (síntesis de trabajo de la Dra. María Silvia Apud Ahualli, publicado en La Gaceta. Tucumán, Argentina, edición del 02.10.2007). En: www.Lagaceta.com.ar/nota/238069/tribunales. Consultada el 05.03.2013).

35 Gómez. En: Porter, K. y otros, Introducción a la Bioética, 2009, pp. 53.

36 Vila-Coro, 1997, pp. 82.

37 Testart y Godin, 2001, pp. 91.

38 Pierri Alfonsín, Milagros. "Filiación y cosa juzgada”, 2008, pp. 170.

39 Pierri, 2008, pp. 171. 
genoma humano, que: a mayor información y publicidad, mayor autonomía del individuo, pensamos que lo mismo se aplica perfectamente respecto al derecho de toda persona de conocer sus orígenes. ${ }^{40}$

Si bien lo expuesto puede sustentarse en la aplicación del derecho a la identidad consagrado por primera vez en nuestro país en la Constitución de 1993, en la Convención de los Derechos del Niño y en diversas normas del Derecho Comparado, además de la jurisprudencia, tanto del Poder Judicial como del Tribunal Constitucional, es necesario de todo modos el poder contar con una norma expresa, a fin de zanjar cualquier duda y darle la contundencia del caso al mencionado derecho.

Además, como lo ha sugerido en Alemania, Andreas Hammel (ginecólogo y director de un banco de donantes de esperma en Erlangen), debería implementarse desde el gobierno un registro de datos en el que se inscriban y conserven todos los datos pertinentes de los "donantes" y de los niños, en forma duradera y segura.

Vale reiterar que nuestro planteamiento se circunscribe al derecho de toda persona de conocer su origen biológico, sin entrar al tema de la determinación de la filiación legal o de los derechos económicos que ella determina, pues se trata de un tema que escapa al presente trabajo y que debe resolverse en el marco de las normas que regulan el Derecho de Familia. En todo caso, vale decir que -como sostiene Morales Godo-, el solo argumento de la existencia de una relación genética no es de por sí suficiente para reclamar la paternidad, teniendo en cuenta razones de orden ético y jurídico; se tendría que pasar por dejar de lado la presunción pater is ${ }^{41}$ a partir de la negación de la paternidad del marido en el caso de la mujer casada, a efectos que el padre biológico pueda reclamar la suya. ${ }^{42}$

Estimamos que, teniendo en cuenta los tiempos que corren, en caso de conflicto entre la paternidad matrimonial establecida por la ley y la evidencia biológica de la paternidad determinada por la realidad, debe tenerse en cuenta el principio del interés superior del niño.

Adicionalmente, estimamos que, para fortalecer la sustentación jurídica del derecho de toda persona nacida mediante tecnologías reproductivas a conocer su origen biológico, puede recurrirse a la bioética, invocándose el principio de autonomía, el principio del respeto a la dignidad de la persona o el consentimiento informado, entre otros, a fin de sustentar un derecho que, finalmente, se sustenta en los valores de la libertad y la justicia.

\section{Bibliografía}

Araya Krstulovic, Rubén. "Secreto y anonimato en la reproducción asistida con donación de gametos", p 3.

En: http://medicina.udd. cl/centro-bioetica/ fi les/2010/08/Secreto-y-anonimato-en-la-reproducci\%C3\%B3n-asistida-con-donaci\%C3\%B3n-de-gametos.pdf. (Consultada el 19.03.2013).

Arias Stella Castillo, Fernando. Derechos Humanos y las sentencias del Tribunal Constitucional que consagran el derecho a investigar la propia filiación. Lima, Instituto de Patología y Biología Molecular “Arias Stella”, 2012.

Díaz de Terán Velasco, Ma. Cruz Díaz. Derecho y nueva eugenesia. Un estudio desde la Ley $35 / 88$, de 22 de noviembre de técnicas de reproducción asistida. Pamplona, Ediciones Universidad de Navarra, S.A., 2005.

Fernández Sessarego, Carlos. Derecho a la identidad personal. Buenos Aires, Astrea, 1992.

García Villaluenga, Leticia y Linacero de la Fuente, María. "El derecho del adoptado a conocer sus orígenes en España y en el Derecho Comparado". En: http://www.fmyv.es/ ci/es/Infancia/lgpi/13.pdf (consultada el 10.03.13).

40 Vásquez, R. - “Etica, Derecho y Fecundación Asistida”, 2004, pp. 96.

41 El término alude a una vieja presunción que proviene del Derecho Romano, en virtud de la cual todo hijo nacido dentro del matrimonio se presume que el del marido, salvo que este lo niegue. Dicha presunción mantiene todavía amplia vigencia, sin embargo viene siendo objeto de revisión a la luz de las nuevas tecnologías y del cambio de diversos patrones sociales.

42 Morales: 2006, p. 426. 
Herrera Campos, Ramón. “Las técnicas de reproducción humana asistida: Su influencia en el Derecho de Familia y en las Sucesiones". En: Genética Humana en el tercer milenio. Aspectos éticos y jurídicos. Madrid, Universidad Internacional de Andalucía, 2003.

Kemelmajer de Carlucci, Aída. El nuevo Derecho de Familia. Bogotá, Pontificia Universidad Javeriana, Facultad de Ciencias Jurídicas. Grupo Editorial Ibáñez, 2010.

Kemelmajer de Carlucci, Aída; Marisa Herrera y Eleadora Lamm. "Con el impulso de la ciencia". En: http: / / www.lanacion.com. ar/1511918-con-el-impulsode-la-ciencia. (Consultada el 22.02.2013).

La Gaceta. Tucumán, Argentina. "La filiación y el derecho a la identidad". Síntesis de trabajo de la Dra. María Silvia Apud Ahualli, edición del 2 de octubre de 2007; en: www.Lagaceta.com.ar/ nota/238069/tribunales. (Consultada el 05.03.2013).

Lütticke, Marcus y Cristina Papaleo. "Hijos de donantes de esperma exigen respuestas". En: Deutsche Welle, edición digital:

http: / / www.dw.de/hi jos-de-donantes-de-es- perma-exigen-respuestas/a-16584888 (consultada el 06.03.2013)

Morales Godo, Juan. "El estatus del concebido y la problemática de la fecundación asistida". En: Revista Derecho. No. 58. Lima, Pontificia Universidad Católica del Perú, 2006.

Olguín Britto, Ana María. "Los derechos de filiación en las técnicas de fecundación artificial”. En: La Familia: Naturaleza y Régimen Jurídico en el Siglo XX. Jornadas Internacionales de Derecho de Familia .Chiclayo, Universidad Católica Santo Toribio de Mogrovejo, 2007.

Pierri Alfonsín, Milagros. "Filiación y cosa juzgada". En: Revista Aequitas. Año II. Número II. Buenos Aires, Universidad del Salvador, 2008.

Plácido Vilcachagua, Alex. "La Evidencia Biológica y la presunción de paternidad matrimonial”. En: luris Consulto, No. 2. Lima, Universidad San Ignacio de Loyola, enero 2010.

Porter, Kuthy y otros. Introducción a la Bioética. $3^{\mathrm{a}}$. Edición, Méndez Editores, 2009.

Marcó Bach, Francisco Javier y Martha Tarasco Michel.
"Fecundación in vitro y manipulación de embriones". En: Porter, Kuthy y otros. Introducción a la Bioética. $3^{\mathrm{a}}$. Edición, Méndez Editores, 2009.

Romeo Casabona, Carlos María, "El tratamiento y la protección de los datos genéticos". En: Mayor Zaragoza, Federico y Carlos Alfonso Bedate (coordinadores). Gen-Etica. Barcelona, Ariel, 2003.

Symons, Xavier. "Birth defects more likely in IVF children". En: BioEdge. Australia, March 09, 2013, p. 7 (Boletín que se reparte vía correo electrónico).

Testart, Jacques y Christian Godin. El racismo del gen. Biología, medicina y bioética bajo la férula liberal. México, Fondo de Cultura Económica, 2001.

Vásquez, Rodolfo. Del aborto a la clonación. Principios de una Bioética Liberal. México, Fondo de Cultura Económica, 2004.

Vásquez, Rodolfo. "Etica, Derecho y Fecundación Asistida". En: Revista Doxa-19, 1993.

Vila- Coro, María Dolores. Huérfanos biológicos. El hombre y la mujer ante la reproducción artificial. Madrid, ediciones San Pablo, 1997. 